\title{
Hereditary elliptocytosis in two Maltese families
}

\author{
J. L. GRECH, E. A. CACHIA, F. CAllejA, AND F. PUllicino \\ From the Department of Pathology, the Royal University of Malta, and a Paediatric \\ Unit, St. Luke's Hospital, Malta
}

SYNOPSIS The findings in two elliptocytic families are recorded and compared. It is the first report of the anomaly in the Maltese population.

A variable degree of clinical and haematological expression among the members of the two families has been observed, ranging from healthy individuals with normal cell morphology to others with only elliptocytic erythrocytes and mild anaemia.

Two subjects have been studied during anaemic crises, and are considered to represent the homozygous state.

The phenomenon of elliptocytosis was first observed by Dresbach in 1904, and since then several reports of its occurrence in various races have been published. The anomaly is transmitted as a Mendelian dominant (Cheney, 1932; Strauss and Daland, 1937) linked with the $\mathrm{Rh}$ genes but is unrelated to sex (Goodall, Hendry, Lawler, and Stephen, 1953, 1954; Lawler and Sandler, 1954; Marshall, Bird, Bailey, and Beckner, 1954; Morton, 1956; Clarke, Donohoe, Finn, McConnell, Sheppard, and Nicol, 1960). The factors which induce the erythrocytes to assume an oval form at the late reticulocyte stage in this condition are unknown.

Wyandt, Bancroft, and Winship (1941) reviewed 246 cases reported in the literature and recorded their observations in 86 cases. They supported the general view that hereditary elliptocytosis represents a harmless abnormality unassociated with any significant disturbances. This view has been modified since Penfold and Lipscomb (1943) estimated from the number of cases in the literature that at least $12 \%$ of individuals bearing the anomaly manifest signs of increased destruction of red cells. Red cell survival studies published since show that the elliptocytes of patients with haemolytic anaemia have a shortened life span both when transfused into normal recipients (Lipton, 1955) and also when reinjected into the patient (Josephs and Avery, 1955; Blackburn, Jordan, Lytle, Swan, and Tudhope, 1958; Dacie, 1960).

The clinical and laboratory findings in two unrelated Maltese families are reported in this paper.

Received for publication 8 November 1960.
Two members of one of the families are believed to represent the homozygous state.

\section{FAMILY S}

The pedigree of family $S$ is shown in Fig. 1, and the laboratory findings of the members examined in Table $I$.

CASE IV.10 A baby boy was well till the age of 4 months when he was admitted to hospital for gastroenteritis and was then given a blood transfusion. At the age of 17 months he was again referred to the hospital for pallor and splenomegaly. The blood findings at the time (20 June 1956) are included in Table I. There were no Leishman-Donovan bodies in the splenic pulp and the long bones were normal radiologically. The anaemia was not improved with iron and vitamin supplements. On 17 April 1957 he was admitted to hospital for further investigation because of slight icterus and persisting anaemia and splenomegaly.

Laboratory findings The haemogram on 22 April 1957 and other data determined subsequently are shown in Table I.

The blood smear (Fig. 2) showed that $70 \%$ of the red cells were elliptocytes and $24 \%$ microspherocytes; some of the elliptocytes were large and others very small, while rod-shaped, tailed, and bizarre forms were common, and schistocytes were also present. Target cells were not found at any time. Diffuse basophilia and normoblasts were absent. Sickle cells were absent in sodium metabisulphite preparations; no abnormal haemoglobin was detected by paper electrophoresis. The direct Coombs test was negative, and no abnormal antibodies were detected in the serum. The bone marrow showed pronounced erythroid hyperplasia (M.E.R.: 0.94/1.; L.E.R.: 0.73/1.). The saline osmotic fragility on 22 April was increased: initial lysis was at $0.72 \% \mathrm{NaCl}$ (normal control at $0.44 \%$ ) and was 
TABLE I

LABORATORY FINDINGS FOR EACH MEMBER OF FAMILY $S$

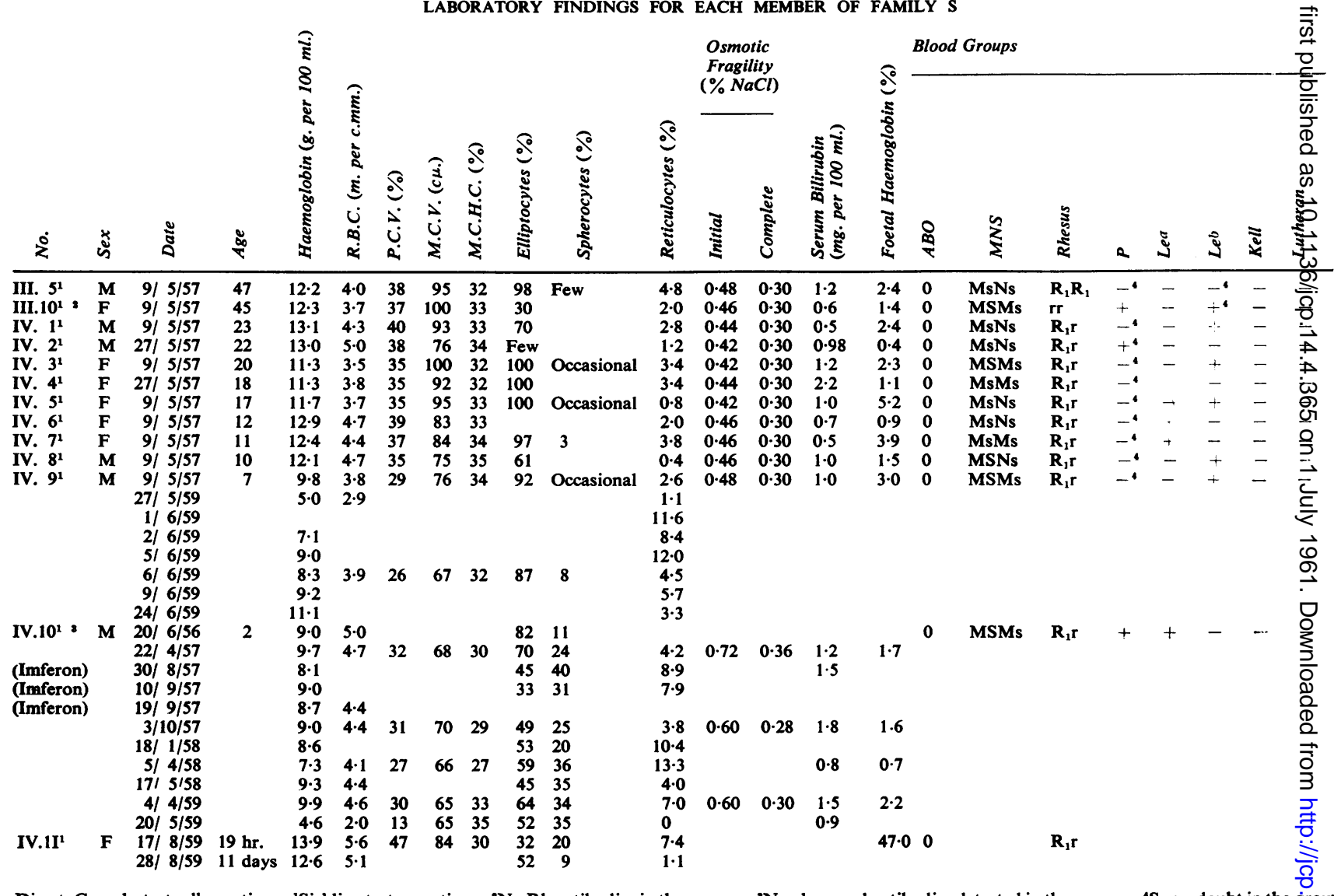

Direct Coombs test: all negative. 'Sickling test: negative. ' ${ }^{2}$ No Rh antibodies in the serum. '

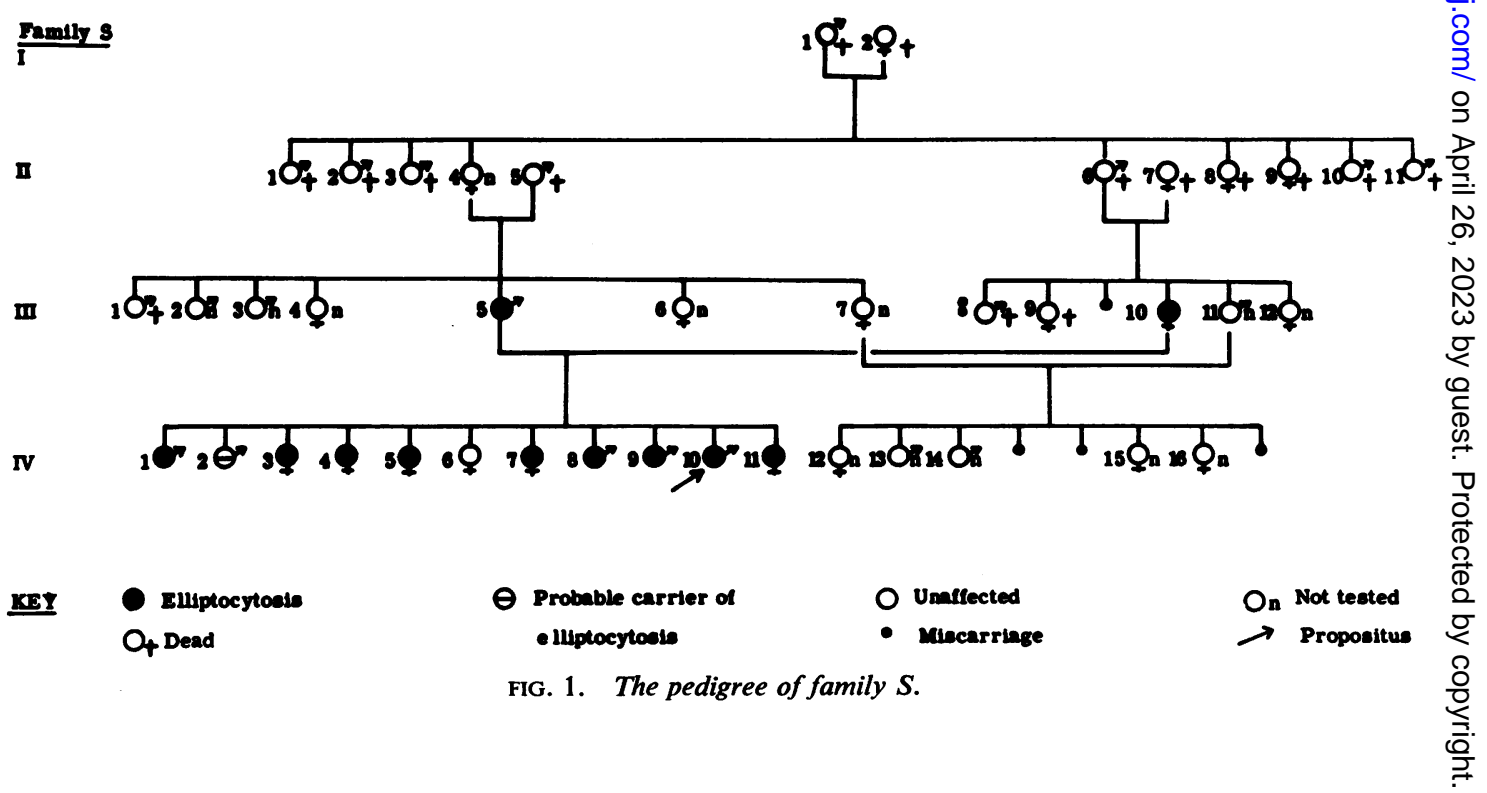




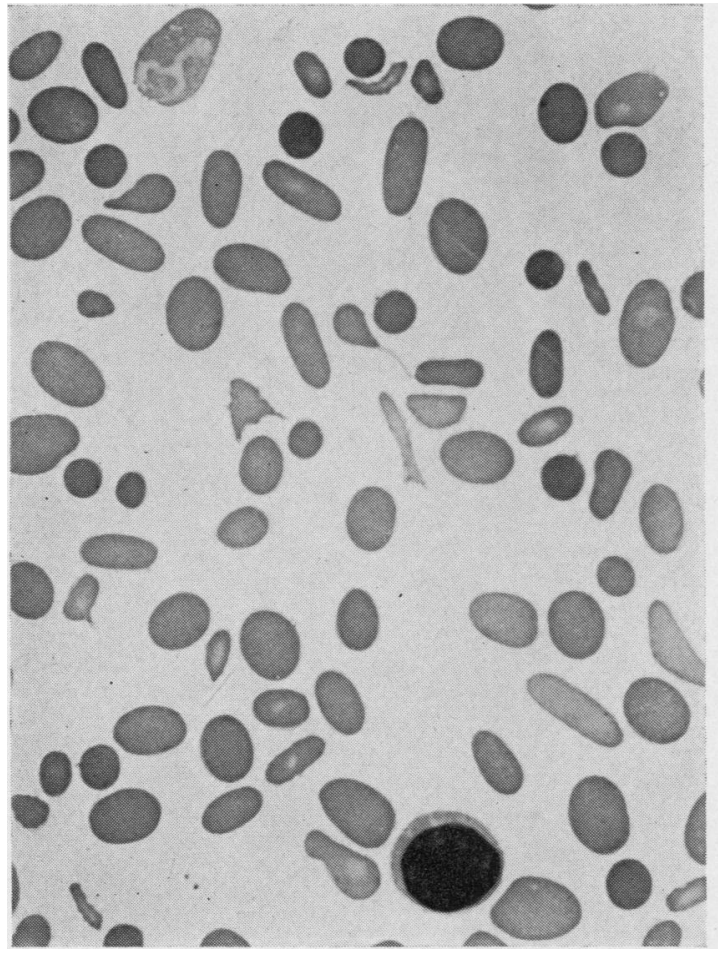

FIG. 2. Photomicrograph of a peripheral blood film made from Case IV.10 of family $S(\times 900)$. complete at $0.36 \% \mathrm{NaCl}$ (normal control at $0.30 \%$ ). The plasma bilirubin level was $1.2 \mathrm{mg}$. per $100 \mathrm{ml}$. and excess urobilin was present in the urine. Turbidity tests of liver function and the serum electrophoretic pattern were normal.

Course Oral iron was given but soon had to be suspended because the child started to vomit after each dose. The child's condition improved slightly, and he was followed up as an out-patient. In April 1958 he was treated for otitis media, and there was no remarkable change in his condition then.

In an attempt to improve the anaemia, two courses of intramuscular iron (Imferon) were administered at an interval of 16 months without benefit. He was re-investigated in April 1959 and no significant changes found.

In May 1959, he was taken ill with fever (T. $101^{\circ} \mathrm{F}$.), increased pallor and polylymphadenitis, and was readmitted to hospital nine days after the onset. The physical findings on admission were: temperature $100^{\circ} \mathrm{F}$; pulse rate 144 per minute; respiration 40 per minute; scanty rales at both lung bases; spleen palpable $4 \mathrm{~cm}$. below costal arch; enlarged soft mobile lymph nodes in neck, axillae, and groins.

The relevant haematological findings at this time are listed in Table I. Blood culture, serum agglutination against Salm. typhi and Br. melitensis, Paul Bunnell test, and Sabin's dye and toxoplasma fixation tests were all negative. He was transfused with $150 \mathrm{ml}$. group $\mathrm{O} \mathrm{Rh}$ positive blood, and given penicillin 500,000 units daily. The temperature resolved by lysis, and the child was afebrile after 10 days' treatment. The changes in the haemoglobin, reticulocyte, and leucocyte counts recorded during this period are shown in Fig. 3.

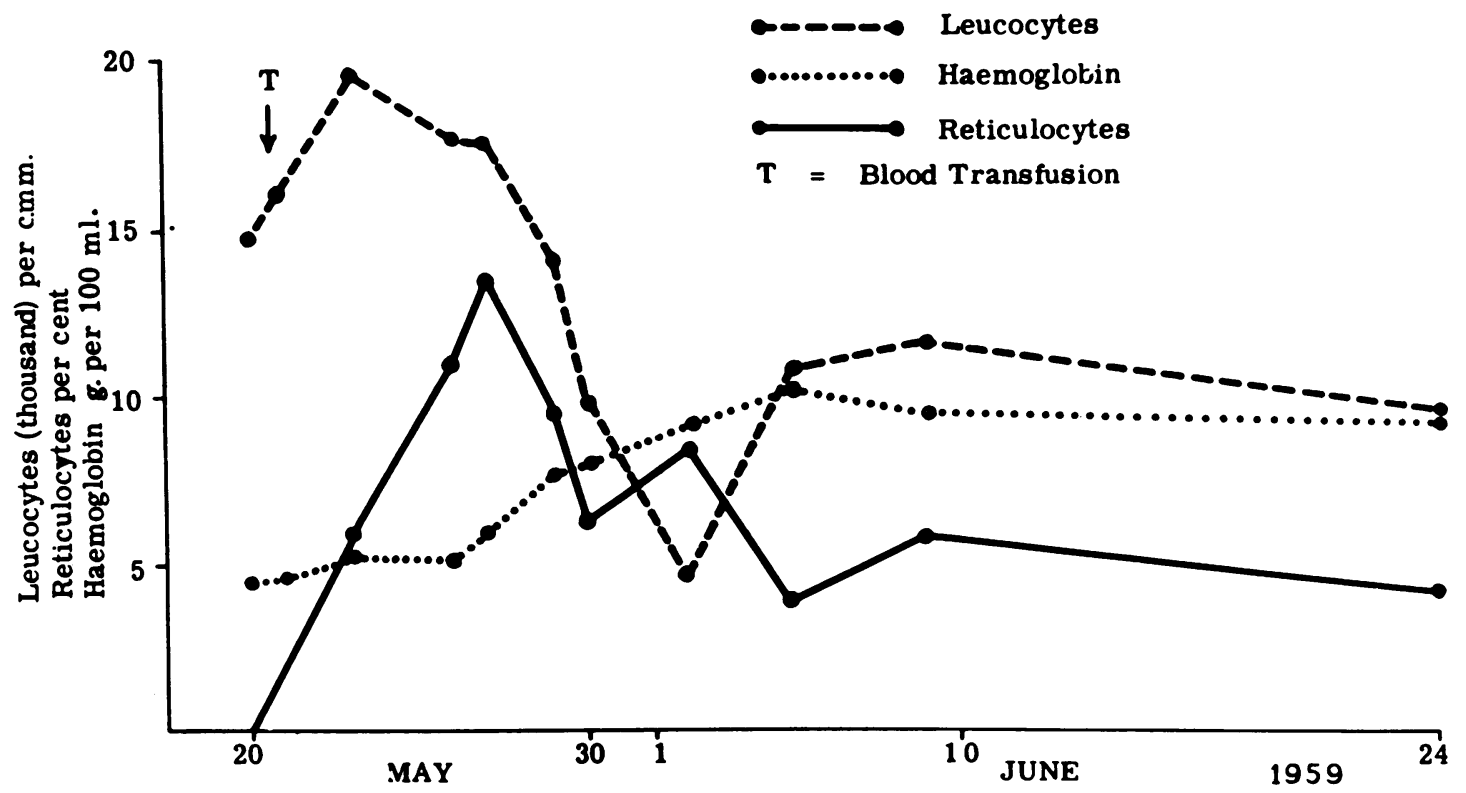

FIG. 3. Curves showing changes in leucocyte and reticulocyte counts and haemoglobin level in Case IV.10 during an 'aplastic' crisis. 


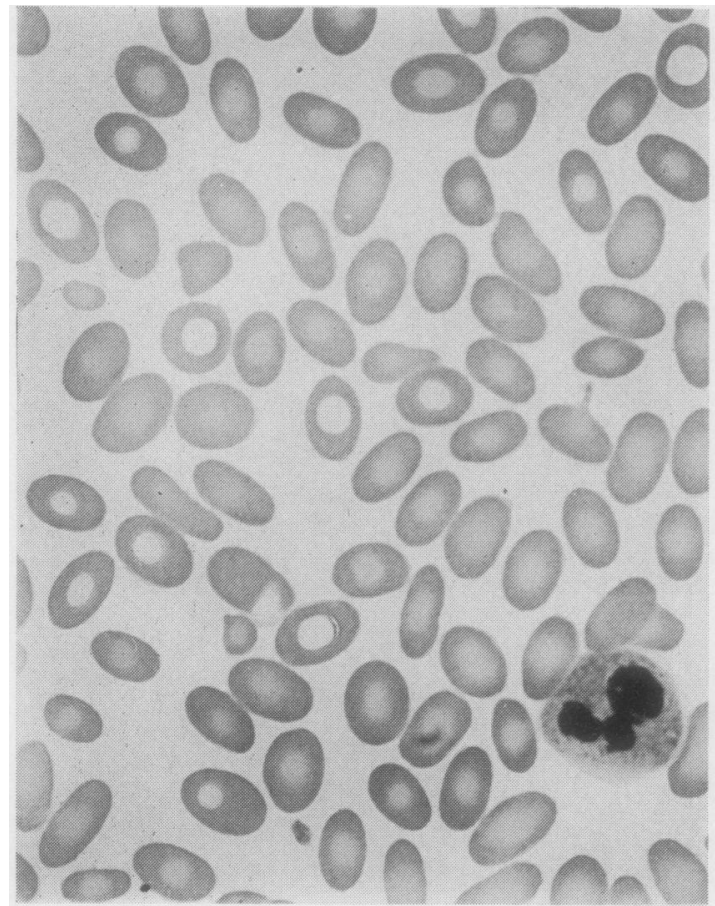

FIG. 4. Photomicrograph of a peripheral blood film made from the father of Case IV.10 of family $S(\times 900)$.

Family study Both parents are of Maltese stock and are first cousins. They and all their progeny have been investigated. There is no history of abortions or stillbirths.

Both parents have elliptical erythrocytes in blood films, and are mildly anaemic. Almost all the erythrocytes of the father (Fig. 4) are elliptocytic or ovalocytic. The number of elliptocytes in the mother (Fig. 5) is much smaller. Only two of the siblings (IV.2, IV.6) do not show evidence of elliptocytosis; the remaining siblings have an elliptocyte count ranging between 30 and $100 \%$. Evidence of increased red cell destruction was found in some of the members. The direct Coombs test was negative in both parents and siblings, while no Rhesus antibodies were detected in the mother's serum. No abnormal haemoglobin was detected by paper electrophoresis but six of the members have a significant increase in $\mathrm{Hb} F$ levels.

The family history of both parents was unrevealing.

\section{FAMILY $\mathbf{K}$}

The pedigree of family $\mathrm{K}$ is shown in Fig. 6. In Table II are recorded the haematological findings of the members investigated.

CASE v.13 A boy, the third in the family, was healthy until the age of 5 years when he suffered from bronchitis which responded to terramycin, and a few weeks later he

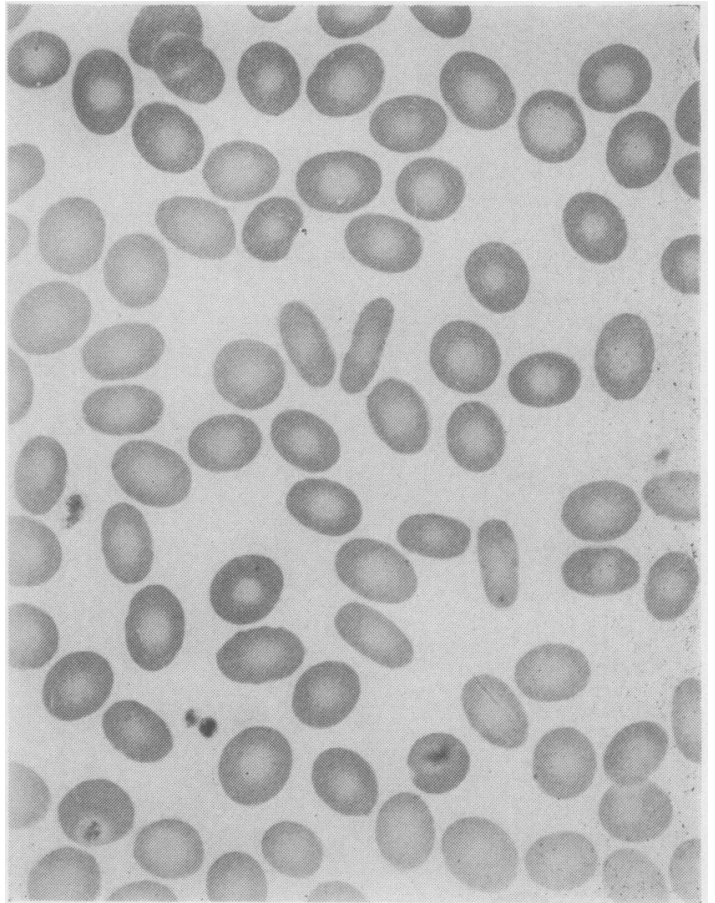

FIG. 5. Photomicrograph of a peripheral blood film made from the mother of Case IV.10 of family $S(\times 900)$.

developed measles. This in turn was followed by a period of low-grade pyrexia, and pallor was noticed for the first time. He was referred to the out-patient department for investigation and on examination no physical signs, apart from pallor, were detected. Routine blood examination showed elliptocytes.

Laboratory findings The haemogram is recorded in Table II. The blood smear (Fig. 7) showed definite elliptocytes and ovalocytes, and only rare microspherocytes. There was marked anisocytosis, but bizarrely shaped erythrocytes were scanty. There were no target cells. Basophilic stippling was present but no normoblasts.

The direct Coombs test was negative. No abnormal $\mathbf{H b}$ was detected by electrophoresis, and the $\mathrm{Hb} F$ level was well within normal. The bone marrow was not examined.

Course The child was followed up for a period during which there was no significant alteration in the haematological findings, except for the presence of spherocytes and poikilocytes in blood films, which were not a feature in previous films. The liver was palpable $3 \mathrm{~cm}$. below the costal arch at this time. He has been in apparent good health since.

Family study The mother of the propositus is of Maltese stock, while one of the father's ancestors is of English extraction. Of the eight pregnancies, two (the fourth and the seventh) terminated in an abortion, and the sixth was a stillbirth. 
Family K

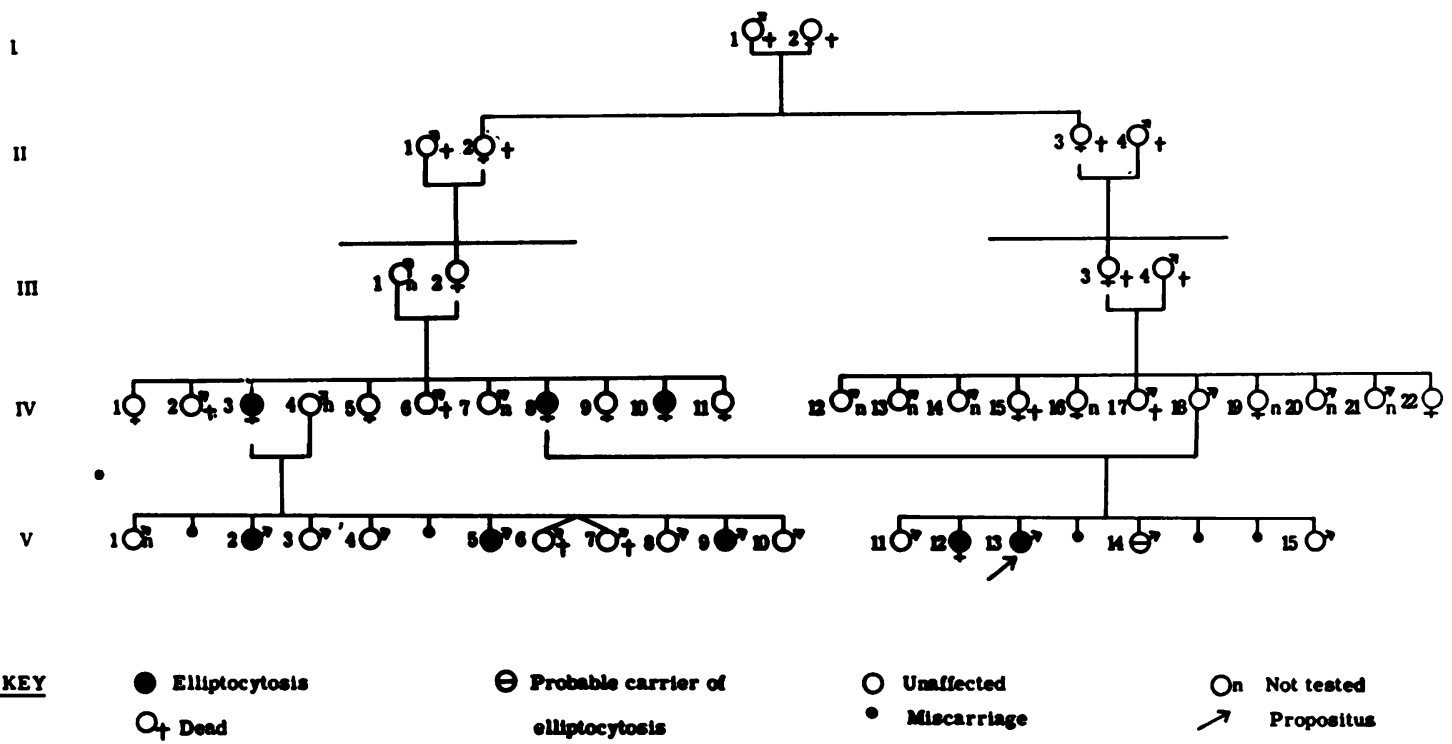

FIG. 6. The pedigree of family $K$.

TABLE II

LABORATORY FINDINGS FOR EACH MEMBER OF FAMILY $K$

๗ั้ ธัँ ะั
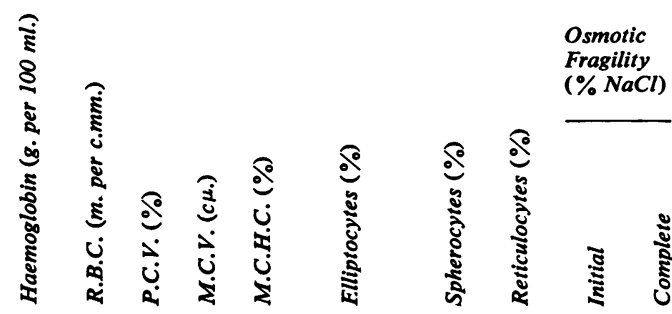

$\begin{array}{llll}\text { F } & 10 / 12 / 57 & 65 & 18.0 \\ \text { F } & 10 / 12 / 57 & 41 & 15.0\end{array}$

$\begin{array}{llll}\text { F } & 10 / 12 / 57 & 38 & 14 \cdot 7\end{array}$

F $10 / 12 / 57 \quad 34 \quad 16 \cdot 2$

F $4 / 12 / 57$

F $10 / 12 / 57$

F $10 / 12 / 57$

F $10 / 12 / 57$

M $14 / 12 / 57$

F $10 / 12 / 57$

M $2211 / 58$

M 24/2/58

M 24/2/58

M 24/2/58

M 24/2/58

M 24/2/58

M 24/2/58

M 4/12/57

F $4 / 12 / 57$

M 4/12/57

18/ $1 / 58$

$2 / 8 / 58$

$\begin{array}{lr}\text { M } & 4 / 12 / 58 \\ M & 30 / 8 / 58\end{array}$

16/10/58 4 mth. 11:1 4.9

$$
\begin{aligned}
& 16 \cdot 2 \\
& 14 \cdot 4 \\
& 18 \cdot 0
\end{aligned}
$$

18.0

$14 \cdot 7$

$16 \cdot 2$

$\begin{array}{llllll}15.6 & 5.0 & 46 & 92 & 34 & \begin{array}{l}\text { Rare } \\ \text { Occasional }\end{array}\end{array}$

15.0 Occasional

$\begin{array}{rrrrrr}9.5 & 3.6 & 31 & 86 & 33 & 78\end{array}$

78

$15 \cdot 7$

$14 \cdot 3$

$12 \cdot 0$

$14 \cdot 3$

$12 \cdot 5$

$12 \cdot 9$

$\begin{array}{llllll}14.1 & 4.6 & 41 & 89 & 34 & \text { Rare }\end{array}$

$\begin{array}{llllll}14 \cdot 1 & 5 \cdot 0 & 42 & 84 & 34 & 23\end{array}$

$\begin{array}{llllll}11 \cdot 7 & 4 \cdot 7 & 39 & 83 & 30 & 100\end{array}$

$11 \cdot 6$

$\begin{array}{llll}12 \cdot 1 & 4 \cdot 4 & 84\end{array}$

$\begin{array}{lllll}14.4 & 5.8 & 43 & 74 & 34\end{array}$

$\begin{array}{rrrrr}3.7 & 35 & 95 & 32 & 6 \\ 4.9 & & & & 3\end{array}$

Fragility

$\mathrm{NaCl}$

ing test: negative. $\quad$ 'Some doubt in the grouping.

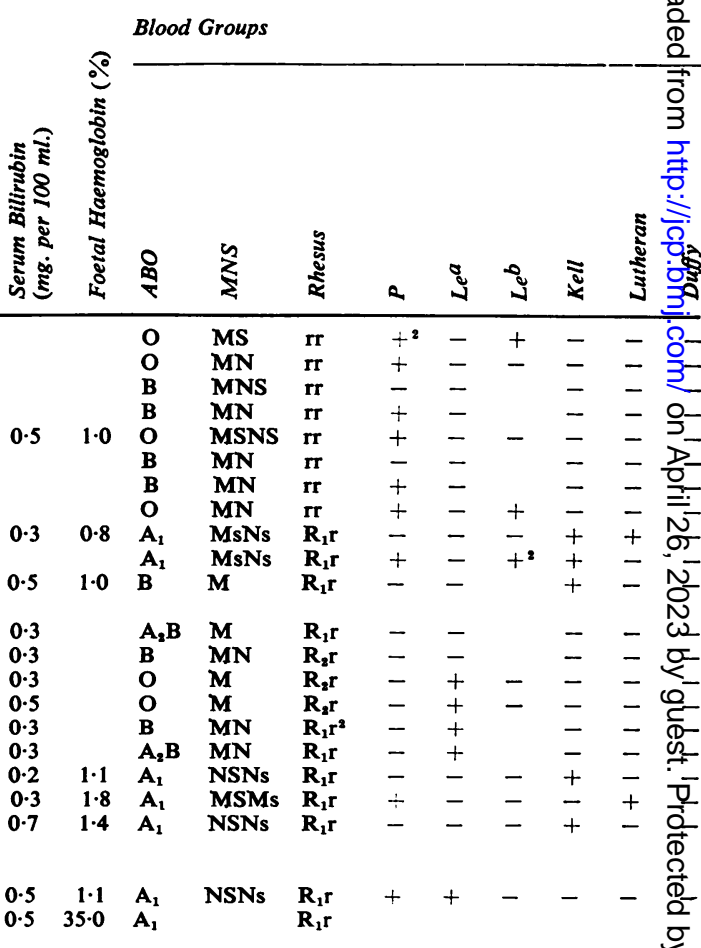

융 


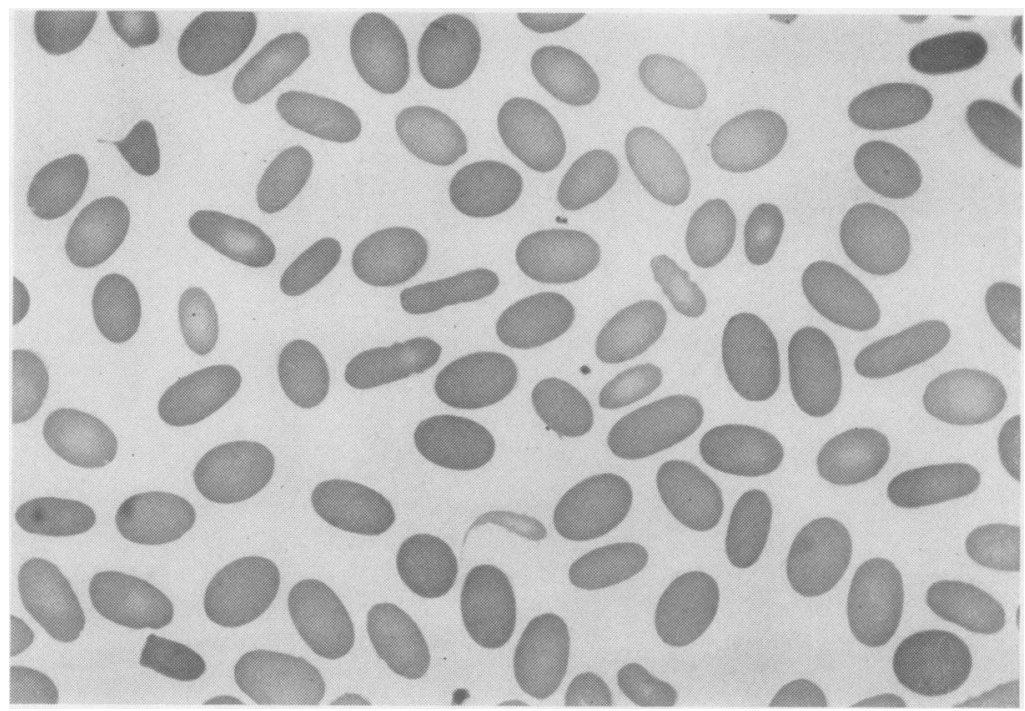

FIG. 7. Photomicrograph of a peripheral blood film made from Case V.13 of family $K(\times 900)$.

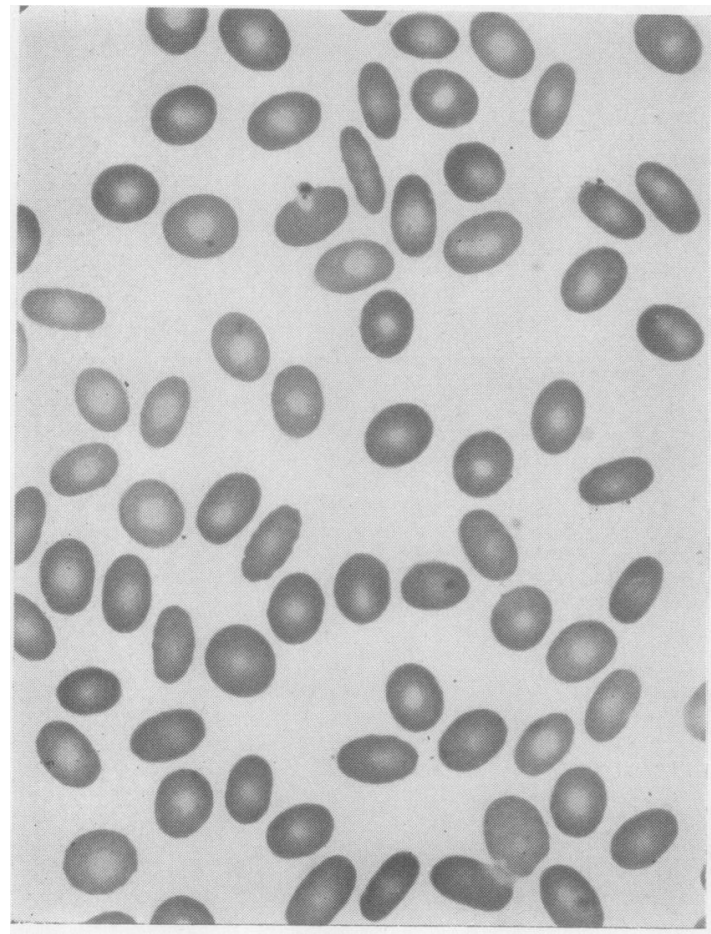

FIG. 8. Photomicrograph of a peripheral blood film made from the mother of Case V.13 of family $K(\times 900)$.

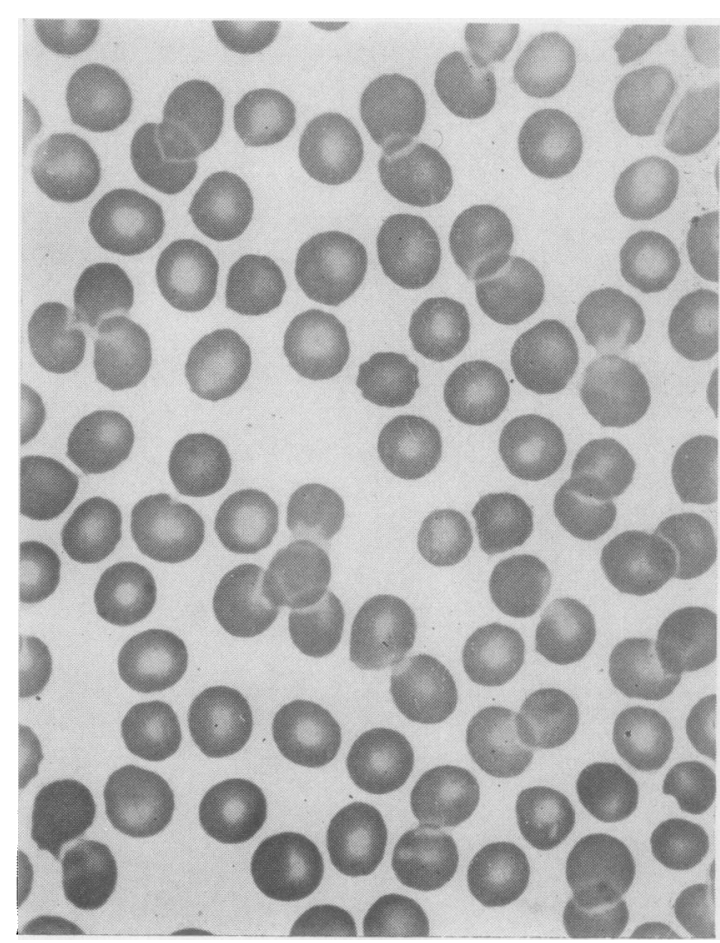

FIG. 9. Photomicrograph of a peripheral blood film made from the father of Case V.13 of family $K(\times 900)$. 
The peripheral blood film (Fig. 8) of the mother (IV.8) and that of another of her children (V.12) show elliptocytosis, but that of the father (IV.18) shows only round cells (Fig. 9). Only the propositus is anaemic; both affected siblings show a mild reticulocytosis.

In all, 22 members of family $\mathrm{K}$ have been investigated. The other branch of the family (V.1 to 10) are the children of unrelated parents. There are two abortions in this family, and a twin pregnancy terminated prematurely, both infants dying in the third month, following a respiratory infection. The blood of three of the seven siblings examined shows definite elliptocytosis, and that of a fourth shows a preponderance of round cells with an appreciable number of oval rather than elliptical forms. Anaemia was present in two of the three affected siblings. The reticulocyte count was raised in one of the affected siblings who is also suffering from rheumatic endocarditis, and in his brother who has oval but no elliptical cells.

Three of the members in sibship IV.1 to 11 showed the anomaly but none were anaemic. The maternal grandmother and a paternal aunt of the propositus were normal.

\section{DISCUSSION}

CRITERIA FOR DIAGNOSIS Several criteria have been proposed for the diagnosis of elliptocytosis (Günther, 1928; Hedenstedt, 1947; Florman and Wintrobe, 1938; Lambrecht, 1938) but the work of Wyandt et al. (1941) indicates that $0 \cdot 2 \%$ of normal subjects have between 10 and $15 \%$ oval red cells in their peripheral blood. Among the 35 members in the two families under study, 17 have an elliptocyte count ranging between 30 and $100 \%$; in two the count is between 20 and $25 \%$, and in the remaining 16, elliptocytes are either absent or number less than $1 \%$. We believe that an elliptocyte count above $20 \%$ in any subject whose near relatives show unquestionable evidence of elliptocytosis constitutes the full carrier state. On this basis 11 members in family $\mathrm{S}$ and eight members in family $\mathbf{K}$ are full carriers.

GENETIC CONSIDERATIONS Both parents (III.5 and III.10) in family $S$ carry the anomaly and are first cousins. We were able to find one report (Lipton, 1955) in the literature of such an occurrence, and possibly a second was one of the cases reported by Lendvai (1949). Wyandt et al. (1941) encountered the anomaly in both parents in one instance, but there was no consanguinity. The only living grandparent (II.4) has refused to be examined. Of the 11 children in this sibship, only two have round cells, and one of them (IV.2) does show a few elliptocytes.

The parents in family $K$ too are related but it is only the mother who shows the anomaly. The father and one of his sisters have only round cells. Two of the five siblings show the anomaly; the elliptocyte count of the propositus (V.13) is $100 \%$, that of the other sibling (V.12) is $23 \%$. Yet another brother has
$10 \%$ elliptocytes and may well represent the 'occult' trait. In sibship V.1 to 10 , three members have 78 to $85 \%$ elliptocytes. Three of the seven antecedents examined in sibship IV.1 to 11 have an elliptocyte count ranging between 24 and $57 \%$.

We could not produce any evidence for linkage of the gene for elliptocytosis with any of the $\mathrm{Rh}$ genes, both parents in both families being homozygous for the latter genes. Our observations agree with previous reports on the absence of sex linkage, and we were also unable to detect associated skeletal abnormalities (Günther, 1928; Gallais, Collomb, and Miletto, 1956; Barnett and Brown, 1957), chronic leg ulceration (Evans, 1943), or a reduction in the elliptocyte count in succeeding generations (McCarty, 1934).

HAEMATOLOGICAL STUdies In family S, IV.9 and IV.10 are suffering from overt haemolytic anaemia, while other members (III.5, III.10, IV.3, IV.4, and IV.5) have a mild degree of anaemia and macrocytosis (Dacie, Mollison, Richardson, Selwyn, and Shapiro, 1953; McBryde, Hewlett, and Weisman, 1956). The slightly raised reticulocyte counts and serum bilirubin levels are evidence of a compensated haemolytic process (Holst-Larsen, 1947).

Only one member (V.2) out of the 22 examined in family $K$ is anaemic, but the anaemia may be due to the rheumatic endocarditis rather than to the elliptocytosis. Slightly raised reticulocyte counts were, however, found in the majority of the elliptocyte members but the serum bilirubin levels in the same subjects were normal (Wyandt et al., 1941; Kirkegaard and Larsen, 1942; Holst-Larsen, 1947.) The blood of unaffected members, with one exception, have a somewhat raised $\mathrm{Hb}$ value, together with a mild macrocytosis in blood films. Similar observations have been previously recorded by Stephens and Tatelbaum (1935), Wyandt et al. (1941), and by Blackburn et al. (1958).

The lower $\mathrm{Hb}$ values in our series were invariably associated with elliptocytosis and normal haematocrit indices, except in the two subjects with manifest haemolytic anaemia.

Spherocytic microcytes and micro-elliptocytes (Fig. 2) were found in significant numbers in only one instance. This finding has been reported both before (Lipton, 1955) and after splenectomy (Wilson and Long, 1953). Splitting of erythrocytes of an infant has been observed under the microscope (Lipton, 1955), and microspherocytes in elliptocytic haemolytic anaemia may originate by this process.

We have, in agreement with previous observers, noted that the change in contour occurs at the late reticulocyte stage. It has been our experience, however, that the elliptocyte count is appreciably lower 
in brilliant cresyl blue preparations than it is in Romanowsky-stained films.

Strauss and Daland (1937) noted that the saline osmotic fragility was normal in the absence of anaemia. Our findings lend support to this view though a marked increase in fragility was observed in one of the proposita (IV.10, family S).

Sicklaemia and hereditary elliptocytosis may coexist (Evans, 1943; Fadem, 1949; Charles and Suitters, 1959; Clarke et al., 1960). The test for sickling was negative in 23 of the members in our series. We have also failed to detect any abnormal $\mathrm{Hb}$ by paper electrophoresis.

Normal Hb F levels are reported to be a feature of elliptocytosis by Motulsky, Singer, Crosby, and Smith (1954), Wilson and Long (1953), Lipton (1955), Plissier, Mechali, Delons, and Fulerand (1957) but Singer, Chernoff, and Singer (1951), and White and Beaven (1954) recognize the occasional detection of traces of $\mathrm{Hb} \mathrm{F}$. We have detected a slight increase above the accepted normal value in six members in family S. Haemoglobin F values did not correlate with the elliptocyte count, although the lowest values recorded in family $S$ are those of the two nonelliptocytic members.

ELLIPTOCYTOSIS IN INFANCY It was Hunter (1932) who first reported the presence of elliptocytes in infancy. It is now established that the anomaly may be manifest at birth and the elliptocyte count reaches a peak at about the third month of post-natal life. (Hunter, 1932; Wyandt et al., 1941; Helz and Menten, 1944). In Lipton's case (1955) hereditary elliptocytosis was complicated by haemolytic anaemia as early as the first month. Similar observations were made by Josephs and Avery (1955).

One member in our series (V.15, family $\mathrm{K}$ ) was studied at the age of 2 months. A mild anaemia, but only a small number of oval erythrocytes were present. At 4 months the number of oval cells was even less. We have also studied another member (IV.11, family S) 19 hours after birth. In contrast to the former infant, her $\mathrm{Hb}$ level was low at this time and lower still subsequently, while the elliptocyte count rose from $32 \%$ to $52 \%$ within 11 days. This change was accompanied by a sharp fall in the reticulocyte count. We have been prevented from following the infant further, but there was already enough evidence to show that she, like most of her family, is a full carrier.

ELLIPTOCYTOSIS AND ANAEMIC CRISES The association of elliptocytosis with haemolytic anaemia is now well established in the literature. In general, if appears that an infection often provokes a crisis. Another complication which is perhaps less welkn recognized is the development of an 'aplastic' crisis $\overrightarrow{0}$ We have been able to study concomittantly twomembers in family S (IV.9 and IV.10) during such $\vec{\omega}$ an episode. Both presented clinically and haemato logically the same features. Reticulocytes were absent? in the peripheral blood, while immature granulocytes, $\vec{A}$ including myeloblasts, were present. As the reticulocyte count steadily rose, the immature granu- $\omega$ locytes disappeared. In one instance (IV.10), the child was transfused but his brother (IV.9) recovered? spontaneously.

CLINICAL VARIATION IN ELLIPTOCYTIC FAMILIES The findings in the two families presented suggest the following grouping: (a) Normal, only round erythro-cytes present; (b) occult trait, erythrocytes mainly응 round and elliptocytes less than $20 \%$; (c) ellipto-s cytosis, elliptocytes over $20 \%$, no haemolysis; $(d)$ elliptocytic haemolytic anaemia (compensated), elliptocytes over $20 \%$, anaemia not present, minor degrees of haemolysis; (e) elliptocytic haemolytic $\Rightarrow$ anaemia (uncompensated), elliptocytes over $20 \%$, continuous anaemia, anaemic crises. The distribution? in the two families is shown in Table III.

Admittedly the classification of any one member is not as obvious and easy as may be inferred. The distinction between the normal and the occult trait? is somewhat arbitrary, and can only be deduced by comparing the findings with the overall picture within ${ }_{3}$ the family. The compensated forms of elliptocytic haemolytic anaemia present some features suggesting $\textrm{ }$ the uncompensated forms, and minor degrees of anaemia may be due to other secondary causes. We have thus adopted a somewhat conservative ap- N proach in our grouping. It can be readily seen from our data that in only a few members is the distinction? sharply demarcated.

It is, however, significant that nine of the 11 ?

TABLE III

DISTRIBUTION OF CLINICAL VARIATION IN THE TWO FAMILIES

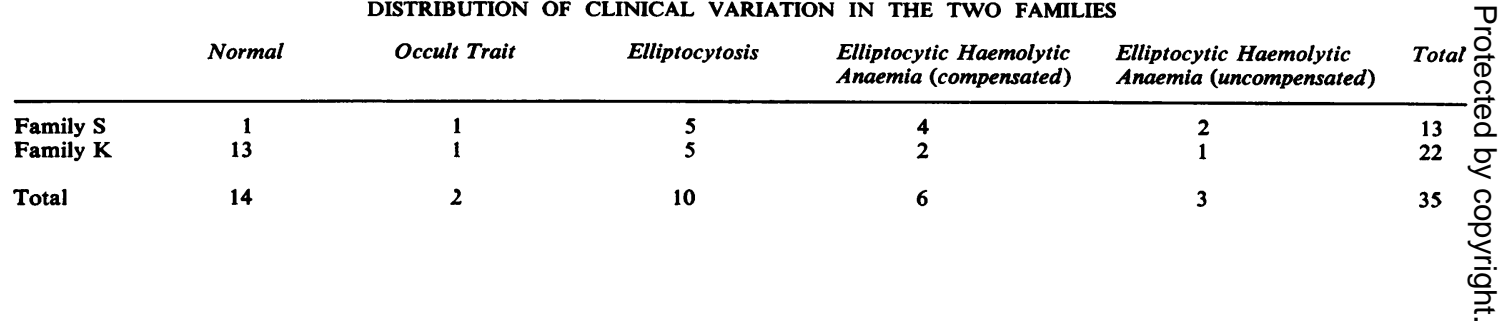


children of affected consanguineous parents definitely show the anomaly, and that two of them have presented with haemolytic or 'aplastic' crises during the period of our study. The latter two siblings (IV.9 and IV.10) have been considered to represent the homozygous state. This seems to be an exceptionally rare occurrence. In the case reported by Wyandt et al. (1941) the parents were not related, and in Lipton's case (1955) the relationship of the parents was more distant than that reported here.

We are grateful to Professor J. V. Dacie, Postgraduate Medical School, London, for helpful criticism of the manuscript. We acknowledge the generous cooperation of Dr. Sylvia D. Lawler, Galton Laboratory, University College, London, for carrying out the genotyping.

\section{REFERENCES}

Barnett, R. N., and Brown, D. S. (1957). J. Mt Sinai Hosp., $24,706$. Blackburn, E. K., Jordan, A., Lytle, W. J., Swan, H. T., and Tudhope, G. R. (1958). J. clin. Path., 11, 316.

Charles, L. J., and Suitters, B. T. (1959). W. Afr. med. J., 8, 102.

Cheney, G. (1932). J. Amer. med. Ass., 98, 878.

Clarke, C. A., Donohoe, W. T. A., Finn, R., McConnell, R. B., Sheppard, P. M., and Nichol (1960). Ann. hum. Genet., 24, 283.

Dacie, J. V. (1960). The Haemolytic Anaemias, 2nd ed. Pt. I, pp. 162-163. Churchill, London.

—, Mollison, P. L., Richardson, N., Selwyn, J. G., and Shapiro, L. (1953). Quart. J. Med., 22, 79.

Dresbach, M. (1904). Science, 19, 469.

Evans, W. (1943). J. Path. Bact., 55, 378.
Fadem, R. S. (1949). Blood, 4, 505.

Florman, A. L., and Wintrobe, M. M. (1938). Bull. Johns Hopk. Hosp., 63, 209.

Gallais, P., Collomb, H., and Miletto, G. (1956). Bull. Soc. Path. exot., 49, 677.

Goodall, H. B., Hendry, D. W. W, Lawler, S. D., and Stephen, S. A. (1953). Ann. Eugen. (Lond.), 17, 272. (1954). Ibid, 18, 325.

Günther, H. (1928). Dtsch. Arch. klin. Med., 162, 215.

Hedenstedt, S. (1947). Acta chir. scand., 95, Suppl. 128.

Helz, M. K., and Menten, M. L. (1944). J. Lab. clin. Med., 29, 185.

Holst-Larsen, T. (1947). Nord. Med., 34, 925.

Hunter, W. C. (1932). Ann. intern. Med., 6, 775.

Josephs, H. W., and Avery, M. E. (1955). Pediatrics, 16, 741.

Kirkegaard, A., and Larsen, K. (1942). Acta med. scand., 110, 510.

Lambrecht, K. (1938). Ergebn. inn. Med. Kinderheilk., 55, 295.

Lawler, S. D., and Sandler, M. (1954). Ann. Eugen. (Lond.), 18, 328. Lendvai, J. (1949). Lancet, 1, 582.

Lipton, E. L. (1955). Pediatrics, 15, 67.

McBryde, R. R., Hewlett, J. S., and Weisman, R., Jr. (1956). Amer. J. med. Sci., 232, 258.

McCarty, S. H. (1934). J. Lab. clin. Med., 19, 612.

Marshall, R. A., Bird, R. M., Bailey, H. K., and Beckner, E. (1954). J. clin. Invest., 33, 790.

Morton, N. E. (1956). Amer. J. hum. Genet., 8, 80.

Motulsky, A. G., Singer, K., Crosby, W. H., and Smith, V. (1954). Blood, 9, 57.

Penfold, J. B., and Lipscomb, J. M. (1943). Quart. J. Med., n.s. 12, 157.

Plissier, M., Mechali, D., Delons, S., and Fulerand, G. (1957). Maroc méd., 36, 253.

Singer, K., Chernoff, A. I., and Singer, L. (1951). Blood, 6, 413.

Stephens, D. J., and Tatelbaum, A. J. (1935). J. Lab. clin. Med., 20, 375 .

Strauss, M. B., and Daland, G. A. (1937). New Engl. J. Med., 217, 100.

White, J. C., and Beaven, G. H. (1954). J. clin. Path., 7, 175.

Wilson, H. E., and Long, M. J. (1953). Amer. J. Med., 14, 534.

Wyandt, H., Bancroft, P. M., and Winship, T. O. (1941). Arch. intern. Med., 68, 1043. 